\title{
Erratum to: Electroosmotic flow through packed beds of granular materials
}

\author{
Rakesh Saini $^{1,2} \cdot$ Matthew Kenny ${ }^{1,2} \cdot$ Dominik P. J. Barz ${ }^{1,2}$
}

Published online: 17 July 2015

(C) Springer-Verlag Berlin Heidelberg 2015

\section{Erratum to: Microfluid Nanofluid \\ DOI 10.1007/s10404-015-1594-0}

Equation (16) was incorrect in the PDF version of the original publication.

The correct equation is given below:

$$
\begin{aligned}
& \Omega_{0} \equiv \frac{\sigma^{\prime} v_{0}}{g \rho r_{\mathrm{cp}} r_{\mathrm{pb}} v^{\prime}}, \quad \Omega_{1} \equiv \frac{\mu v_{0}}{g \rho r_{\mathrm{cp}}^{2}}, \quad \Omega_{2} \equiv \frac{v_{0}^{2}}{g r_{\mathrm{pb}}}, \\
& \Omega_{3} \equiv \frac{\mu v_{0}(1-\psi)^{2}}{\rho g \psi^{3}} \frac{r_{\mathrm{pb}} l_{\mathrm{pb}}}{d_{\mathrm{p}}^{2} r_{\mathrm{cp}}^{2}} V_{\mathrm{eof}}, \quad \Omega_{4} \equiv \frac{\sigma_{o} \cos \theta_{e}}{g p r_{\mathrm{cp}} r_{\mathrm{pb}}}
\end{aligned}
$$

The PDF version of the original article has been updated with the correct equation.

The online version of the original article can be found under doi:10.1007/s10404-015-1594-0.

Dominik P. J. Barz

dominik.barz@queensu.ca

1 Department of Chemical Engineering, Queen's University, Dupuis Hall 213, Kingston, ON K7L 3N6, Canada

2 Queen's - RMC Fuel Cell Research Centre, 945 Princess Street, Kingston, ON K7L 3N6, Canada 